Research Paper

\title{
Evidence for a Proapoptotic Role of Matrix Metallo- proteinase-26 in Human Prostate Cancer Cells and Tissues
}

\author{
Zahraa I. Khamis¹, Kenneth A. Iczkowski², Yan-Gao Man², Mayassa J. Bou-Dargham¹, and Qing-Xiang \\ Amy Sang ${ }^{\square}$ \\ 1. Department of Chemistry and Biochemistry and Institute of Molecular Biophysics, Florida State University, Tallahassee, FL, USA; \\ 2. Department of Pathology and Laboratory of Medicine, Medical College of Wisconsin, Milwaukee, Wisconsin, USA; \\ 3. The Research Laboratory and International Collaboration, Bon Secours Cancer Institute, Bon Secours Health System, Richmond, VA, USA
}

$\triangle$ Corresponding author: Prof. Qing-Xiang Amy Sang, Ph.D., Department of Chemistry and Biochemistry and Institute of Molecular Biophysics, Florida State University, 102 Varsity Way, Tallahassee, FL 32306-4390, USA; Tel: +1-850-644-8683; Fax: +1-850-644-8281; E-mail: qxsang@chem.fsu.edu

(C) Ivyspring International Publisher. Reproduction is permitted for personal, noncommercial use, provided that the article is in whole, unmodified, and properly cited. See http://ivyspring.com/terms for terms and conditions.

Received: 2015.06.27; Accepted: 2015.10.02; Published: 2016.01.01

\begin{abstract}
Matrix metalloproteinases (MMPs) play intricate roles in cancer progression; some promote invasion and angiogenesis while others suppress tumor growth. For example, human MMP-26/endometase/matrilysin-2 was reported to be either protective or pro-tumorigenic. Our previous reports suggested pro-invasion and anti-inflammation properties in prostate cancer. Here, we provide evidence for a protective role of MMP-26 in the prostate. MMP-26 expression levels in androgen-repressed human prostate cancer (ARCaP) cells, transfected with sense or anti-sense MMP-26 cDNA, are directly correlated with those of the pro-apoptotic marker Bax. Immunohistochemical staining of prostate cancer tissue samples shows similar protein expression patterns, correlating the expression levels of MMP-26 and Bax in benign, neoplastic, and invasive prostate cancer tissues. The MMP-26 protein levels were upregulated in high grade prostate intraepithelial neoplasia (HGPIN) and decreased during the course of disease progression. Further analysis using an indirect terminal deoxynucleotidyl transferase dUTP nick end labeling (TUNEL) assay showed that many tumor cells expressing MMP-26 were undergoing apoptosis. This study showed that the high level of MMP-26 expression is positively correlated with the presence of apoptotic cells. This pro-apoptotic role of MMP-26 in human prostate cancer cells and tissues may enhance our understanding of the paradoxical roles of MMP-26 in tumor invasion and progression.
\end{abstract}

Key words: Endometase, matrilysin-2, Bax, apoptosis, prostate, matrix metalloproteinases, protective role, tumorigenic, and cancer progression.

\section{Introduction}

Matrix metalloproteinases (MMPs) comprise a family of structurally and functionally related zinc-dependent enzymes whose expression is tightly controlled by transcription levels, cellular localization, zymogen activation, and endogenous inhibition. MMPs directly modulate a wide variety of physiologic processes such as embryo implantation, bone remodeling, cell proliferation, migration, apoptosis, and nerve development through cleavage of bioactive molecules affecting these processes. Through prote- olysis of matrix components and associated tissue remodeling, MMPs may affect multiple pathological conditions including neoplasia, inflammation, and vascular diseases [1;2].

By virtue of their proteolytic activity and ability to degrade nearly every component of the extracellular matrix, MMPs have long been considered as mediators of tumor invasion and metastasis. MMP-14 and MMP-9 were found to activate transforming growth factor- $\beta$ (TGF- $\beta$ ) resulting in increased tumor 
proliferation and progression in lung cancer and murine mammary carcinoma cells, respectively [3; 4]. MMP-14, MMP-1, and MMP-3 are involved in tumor cell trafficking in invasive fibrosarcoma and triple negative breast cancer cell lines [5; 6]. Furthermore, MMPs can induce cancer invasion and metastasis through activation of a family of G-protein coupled receptor (GPCR) known as PARs (proteinase-activated receptors), by cleaving their extracellular domain. A fibroblast-derived MMP-1 was reported to promote breast cancer through activation of PAR-1 [7; 8]. Based on the aforementioned roles of MMPs, efforts were made to develop synthetic MMP inhibitors for therapeutic applications. Many papers in the literature discuss the promising use of MMP inhibitors for treatment and prevention of stroke and atherosclerosis [2; 9; 10]. However, MMP inhibitors tested in oncology clinical trials were not successful partially due to the protective and anti-tumorigenic effects of certain MMPs at varying stages of cancer progression [11].

At the primary site of tumor growth, studies revealed protective effects of many MMPs at early stage of tumor development. In a squamous cell carcinoma mouse model, loss of MMP-3 caused elevated growth rate and disease progression as compared to wild-type controls [12]. Carcinomas originating in MMP-3 null mice were associated with reduced leukocyte infiltration, demonstrating a causal role of MMP-3 in host defense [12]. Another study was performed to determine the role of MMP-8 in tumor progression. MMP-8 deficient mice had higher incidence of developing skin tumors than their normal counterparts [13]. The induction of MMP-8 expression through bone marrow transplantation was sufficient to restore protection against tumor development [13]. MMP-12 provides another example of a metalloprotease exhibiting anti-tumorigenic effects. MMP-12 derived from tumor-associated macrophages was correlated with a less aggressive phenotype in squamous cell carcinoma, resulting in a better outcome [14]. Similarly, MMP-9 was shown to have a preventive role during the progression of tumors to the invasive state in transgenic mice [15]. The authors analyzed a mouse model of multistage tumorigenesis induced by HPV-16 oncogenes crossed into an MMP-9 deficient model [15]. They noticed that loss of MMP-9 in the transgenic mice caused reduced keratinocyte proliferation at all neoplastic stages and decreased incidence of invasive tumor. However, tumors arising in MMP-9 deficient mice were more aggressive, higher grade, and poorly differentiated [15]. As with invasion, some MMPs also proved to protect the host against subsequent metastasis [9]. Agarwal et al. found an overexpression of MMP-8 in a non-metastatic breast cancer cell line as compared to its metastatic counterpart [16]. Specific knockdown of MMP-8 in the non-metastatic line increased its metastatic ability [16]. Furthermore, studies on the intracellular function of MMPs revealed their contribution to apoptosis. MMP-3 caused a two-fold increase in the rate of apoptosis in malignant and premalignant hepatocytes when localized to the nucleus [17]. The suggested nuclear targets proteolyzed by MMP-3 include factors related to DNA repair and RNA processing [18]. Under oxidative stress, an intracellular MMP-2 isoform namely NTT-MMP-2 is formed in cardiomyocytes and is thought to activate mitochondrial-nuclear stress pathways causing a subsequent cardiac failure [19]. Therefore, understanding the complex and often paradoxical roles of MMPs in tumorigenesis will help develop better therapeutic strategies aimed at modulating, rather than merely inhibiting, MMPs.

MMP-26, also called endometase or matrilysin-2, is a partially characterized proteinase that was discovered by our group and others [20-23]. Structurally, it shares features with other MMPs such as a signal peptide, a propeptide domain with unique cysteine switch, and a catalytic domain [20]. However as observed with MMP-7 (matrilysin-1), MMP-26 has some atypical features, and is referred to as "minimal domain MMP" because it lacks the linker and hemopexin-like domain common to most family members [20-23]. Additionally, it is associated with the intracellular milieu-unlike most MMPs which are secreted into the ECM-suggesting unorthodox roles in cells and tissues $[24 ; 25]$.

MMP-26 is expressed in normal epithelium and carcinomas such as endometrium, breast, and prostate [20; 25-27]. The levels of this enzyme fluctuate over the course of tumor progression, starting low in normal epithelium, increasing in neoplastic tissue, and ultimately decreasing as cancer progresses to more advanced stages [28; 29]. Similar to other family members, MMP-26 was initially thought to promote tumor progression as its expression was upregulated in human prostate carcinoma when compared to normal or hyperplastic prostate [27; 30]. However, recent evidence suggested a beneficial and protective role of this protease. MMP-26 was shown to play an anti-inflammatory role by downregulating IL-10RB and inhibiting MMP-9 in MMP-26 sense cDNA-transfected androgen-repressed human prostate cancer (ARCaP) cells [31]. Additionally, MMP-26-mediated proteolysis of estrogen receptor $\beta$ $(E R \beta)$ resulted in favorable prognosis and longer survival of breast cancer patients [28-30; 32]. Despite the increased appreciation of the important roles of MMP-26 in cancer over the past few years, its oppos- 
ing effects in cancer progression warrant further investigation. Recent data showed that the ability of MMPs to affect apoptosis can be used to explain this conundrum. Many MMPs have been identified as critical enzymes with opposite roles in apoptosis [33]. However, the direct function of MMP-26 in apoptosis has never been evaluated. Whether this enzyme takes on a pro- or anti-apoptotic role is important, and may explain its anti-tumorigenic properties.

In this study, we report a novel, unexpected, and highly significant function of MMP-26 in apoptosis. ARCaP cell lines and prostate tissue sections were used to evaluate the expression of MMP-26 and apoptotic markers. Three variants of ARCaP cells were investigated in the study: parental ARCaP; MMP-26 sense-transfected ARCaP; and MMP-26 antisense transfected ARCaP. The correlation between MMP-26 and Bax expression levels in cell and tissue studies suggests a function of MMP-26 in apoptosis.

\section{Materials and Methods}

\section{Tissues and Cell Culture}

Slides were cut from paraffin blocks of patients who underwent prostatectomy at the University of Colorado Health Science Center. Human Subject Institutional Review Board approval as "not human subject research" was obtained, according to COMIRB protocol \#10-0774. Androgen-repressed prostate cancer (ARCaP) cells were transfected with sense or anti-sense MMP-26 cDNA as previously described by Zhao et al. [30]. All cells were grown in low-glucose Dulbecco's Modified Eagle's Medium supplemented with $10 \%$ fetal bovine serum in a humidified chamber containing $5 \% \mathrm{CO}_{2}$ at $37^{\circ} \mathrm{C}$.

\section{Western blot}

Western blot analyses were performed by lysing the cells with lysis buffer (30 mM Tris, $7 \mathrm{M}$ urea, $4 \%$ CHAPS, and protease and phosphatase inhibitors ( Halt ${ }^{\mathrm{TM}}$ Protease and Phosphatase Inhibitor Single-Use Cocktail, EDT-free (100X), Prod\#78443, Thermo Scientific, Waltham, MA, USA), followed by vortexing for 1 hour and centrifugation for $15 \mathrm{~min}$ at 15,000 $\mathrm{g}$. Protein extraction and quantification was done using microplate bicinchoninic acid (BCA) protein assay kit as described previously [34]. Aliquots of $25 \mu \mathrm{g}$ of cell lysate were treated with sodium dodecyl sulfate (SDS) sample buffer and loaded onto a $10 \%$ polyacrylamide gel. The gel was electrophoresed at $50 \mathrm{~V}$ for $30 \mathrm{~min}$, then at $100 \mathrm{~V}$ till the end of the separation. Proteins were then electroblotted into a nitrocellulose membrane at $50 \mathrm{~V}$ for 2 hours at room temperature. Following electroblotting, membranes were blocked with $5 \%$ bovine serum albumin (BSA) in Tris-buffered saline/Tween-20 (TBST) buffer. Detection was accom- plished using 1:500 dilution of Bax antibody (cat \#2774, Cell Signaling, Danvers, MA, USA) and 1 $\mu \mathrm{g} / \mathrm{mL}$ dilution of MMP-26 primary antibody established in our laboratory and directed against a peptide derived from MMP-26 metalloproteinase domain which has a sequence of Asp ${ }^{188}$-Lys-Asn-Glu-His-TrpSer-Ala-Ser-Asp-Thr-Gly-Tyr-Asn ${ }^{201}$ selected from the pre-proenzyme [29; 30]. All primary antibodies were prepared in $1 \%$ BSA. This was followed by incubation with horseradish peroxidase-conjugated secondary antibody against the appropriate species for 1 hour. Development of the bands was accomplished by the addition of a 1:1 ratio of Super Signal West Pico-Stable Peroxidase Solution and Luminol/Enhancer Solution (Pierce, Dallas, Tx, USA) and by using Kodak Scientific Imaging Film (cat \#1651496, Kodak, Rochester, NY, USA), Fixer and Replenisher/Developer and Replenisher (cat \#1901859, Kodak, Rochester, NY, USA) according to manufacturer's instructions.

\section{Immunohistochemistry}

Immunohistochemistry was done using 16 benign, 9 HGPIN, and 16 human prostate cancer tissue samples. The procedure for all tissues was done on the Ventana NexES automated immunostainer platform at $37^{\circ} \mathrm{C}$ using the I-VIEW (Ventana Medical Systems, Tucson, Az, USA) enhanced DAB kit with the addition of an Avidin/Biotin Blocking Kit. Sections were retrieved in $10 \mathrm{mM}$ sodium citrate/citric acid buffer ( $\mathrm{pH}$ 5.8) for 5 minutes in a Biocare Decloaking chamber at $125^{\circ} \mathrm{C}(22 \mathrm{psi})$ and subsequently incubated for 32 minutes in a pre-diluted antibody from Ventana; the signal was amplified with a kit containing rabbit anti-mouse heavy and light chains (Amplifier A) and mouse anti-rabbit heavy and light chains (Amplifier B). The primary antibodies Bax (cat \#2774, Cell Signaling, Danvers, MA, USA) and MMP-26 (generated in our lab) were incubated for 30 minutes at concentrations of 1:100 and 1:150 respectively. A Lab Vision UltraVision LP Polymer Detection Kit (cat \#TL-015-HD, Thermo Fisher Scientific, Waltham, MA, USA) was used at half strength for detection. Incubation for 5 minutes with Cardassian DAB (Biocare, Concord, CA, USA) visualized the bound antibody. All slides were counterstained with Mayer's hematoxylin for 2 minutes and photographed using Olympus BH2 BHT microscope at 400× magnification. The average intensity of immunostaining in a specimen was semi-quantitatively rated by a pathologist from 0 to $3+$ in 0.5 intervals. Ratings were assigned for cancer, benign acini, and prostatic intraepithelial neoplasia (when present).

\section{Apoptosis Assay}

Paraffin-embedded human prostate tissue sec- 
tions were placed on positively charged microscope slides and were subjected to an apoptosis assay with a ApopTag Plus Peroxidase In Situ Apoptosis Detection Kit (cat \#S7101, Chemicon International, Temecula, CA, USA) using the protocol provided by the manufacturer. This kit labels apoptotic cells using indirect TUNEL assay through the modification of DNA fragments by terminal deoxynucleotidyl transferase (TdT) for detection of apoptotic cells. After the apoptosis assay, tissue sections were washed with PBS and immunostained with a basal cell phenotypic marker, cytokeratin 34ßE12. Images were taken with an Olympus microscope at $100 \times$ and $400 \times$ magnifications.

\section{Statistical Analysis}

Statistical analysis was performed using non-parametric Wilcoxon signed-rank test. The $p$-value for statistically significant results was set at 0.05 .

A)

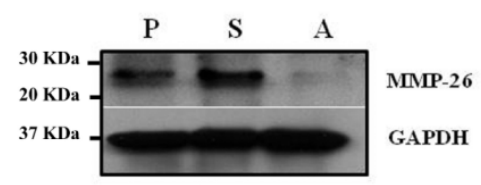

C)

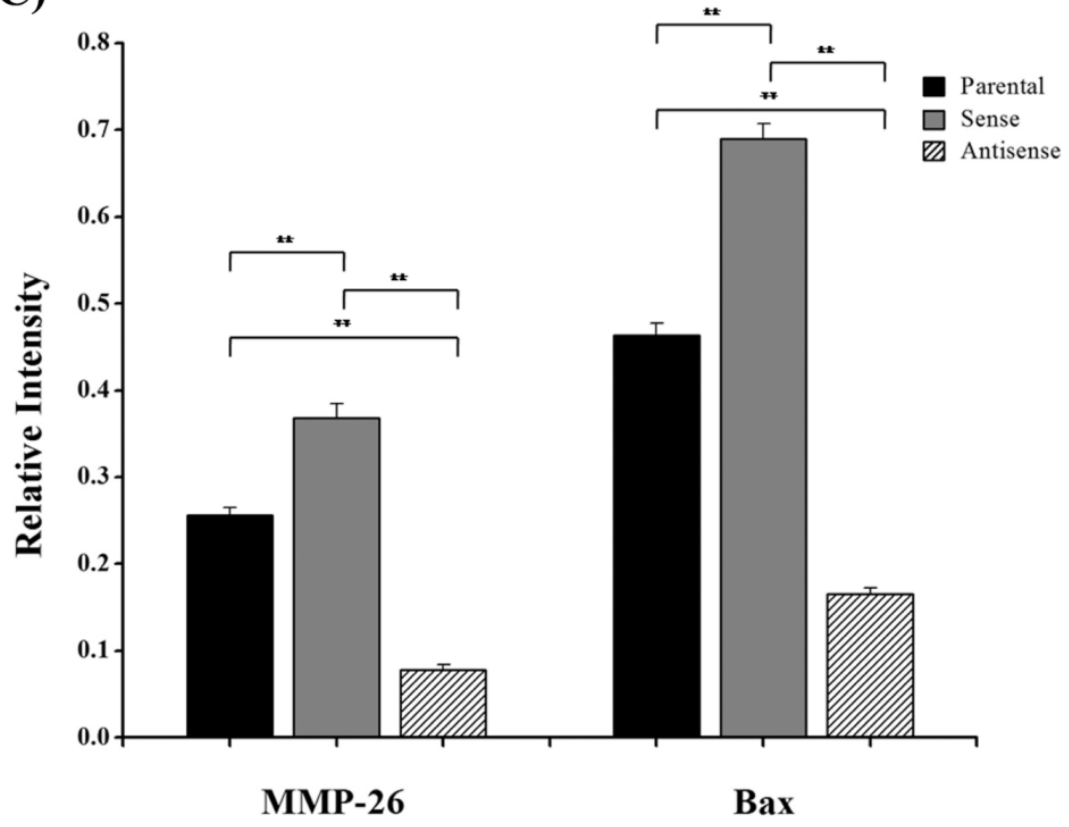

Figure 1: MMP-26 and Bax protein expression. Western blot of MMP-26 protein (A) and Bax (B) in parental ARCaP cells (P), sense MMP-26 cDNA-transfected cells (S) and antisense MMP-26 cDNA-transfected cells (A). GAPDH was used as loading control. C) Bar graph showing MMP-26 and Bax expression normalized to GAPDH. The error bar represents the standard error. The standard errors for MMP-26 expression are 0.0089 in parental ARCaP cells, 0.016 in sense MMP-26 cDNA-transfected ARCaP cells, and 0.0062 in antisense MMP-26 cDNA-transfected ARCaP cells. The standard errors for Bax expression are 0.014 in parental ARCaP cells, 0.017 in sense MMP-26 cDNA-transfected ARCaP cells, and 0.0062 in antisense MMP-26 cDNA-transfected ARCaP cells. **: $\mathrm{p}<0.01$.

\section{Results and Discussion}

Matrix metalloproteinases (MMPs) are critical players affecting the commitment of cells to undergo apoptosis. Although caspases remain the ultimate executors of cell death, apoptosis can be triggered by the effective activation or inhibition of other proteases including MMPs [33-35]. Through proteolysis of biologically active intra- and extracellular substrates, MMPs profoundly influence cell fate and may play opposing roles in apoptosis [33]. Proteolytic cleavage of Fas ligand (FasL), a transmembrane stimulator of the death receptor Fas, by MMP-7 generates soluble FasL which induces either epithelial cell apoptosis [36] or tumor cell resistance to chemotherapeutic drugs [37]. MMP-2 and MMP-9 promote cell death during tissue remodeling while they decrease cancer cell apoptosis during tumor progression [33]. Moreover, expression of MMP-3 in transgenic mice increased the number of apoptotic cells following DMBA (7,12-dimethylbenzanthracene) carcinogen treatment [38].

Here, we have demonstrated that MMP-26 expression is positively correlated with the expression of the pro-apoptotic marker Bax. This correlation was statistically significant in ARCaP cell lines and human tissues. Western blot analysis of MMP-26 (Fig. $1 \mathrm{~A}-\mathrm{C})$ showed high levels of the enzyme in MMP-26 sense-transfected ARCaP cells $(p<0.01)$ and low levels in MMP-26 antisense-transfected cells $(p<0.01)$ as compared to the parental control. Bax expression pattern (Fig. 1B-C) mimicked that of MMP-26 with highest levels in MMP-26 sense-transfected cells $(p<0.01)$ and lowest levels in MMP-26 antisense-transfected cells $(p<0.01)$. Immunohistochemical staining of 20 human prostate tissue sections corroborated the in vitro data. Interestingly, MMP-26 and Bax showed similar patterns of spatial co-localization and expression in adjacent sections (Fig. 2). Observed in the prostatic epithelia, MMP-26 was significantly higher in cancer than benign acini $(p<0.001) \quad$ (Fig. 2A). Tissues with high-grade prostatic intraepithelial neoplasia (HGPIN) exhibited stronger immunoreactivity for MMP-26 than tumor tissues within the same specimens (Fig. 2C). The expression of Bax was also detected in prostatic epithe- 
lium in a pattern similar to that of MMP-26 (Fig. 2B and Fig. 2D). Bax was highly expressed in HGPIN and cancer as compared to non-neoplastic epithelium $(p<0.001)$. Moreover, Bax expression was the highest in HGPIN with significantly lower levels $(p<0.01)$ in cancer within the same tissue specimen (Fig. 3). The expression patterns of both proteins in the tissues were statistically significant $(p<0.01)$ except for MMP-26 expression in HGPIN and cancerous glands (Fig. 3), which may be attributed to the spatial and temporal proximity between these two stages of cancer progression.
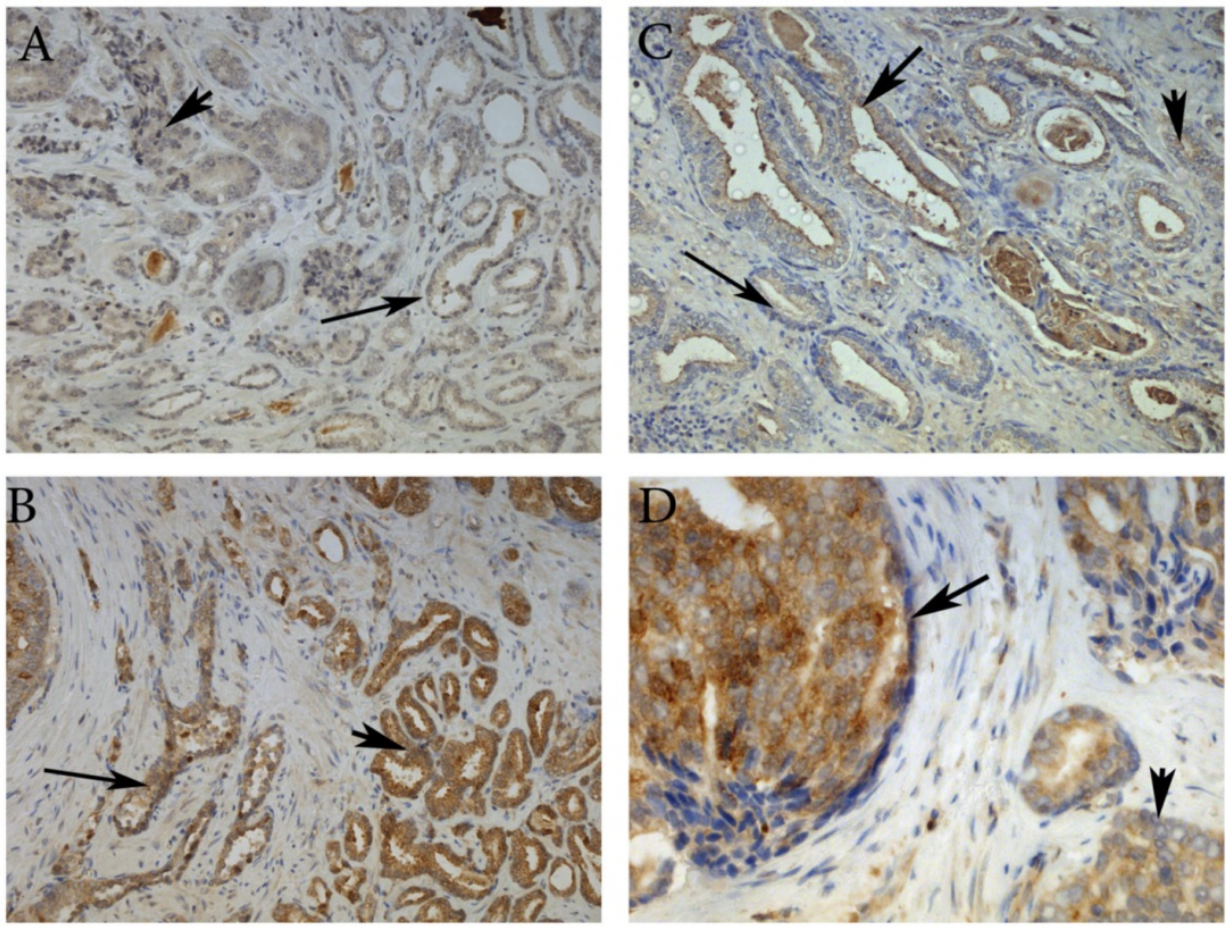

Figure 2: Representative images of MMP-26 and Bax immunohistochemical staining in benign glands (thin arrow), HGPIN (thick arrow) and cancer glands (arrowhead). MMP-26 immunostaining was higher in cancer than benign glands (A) and more intense in HGPIN than in cancer (C). Similarly, Bax was more immunoreactive in tumor cells than in benign acini (B) and higher in secretory cells of HGPIN than in invasive cancer (D). Images $2 \mathrm{~A}$ and $2 \mathrm{~B}$ were taken at $100 \mathrm{X}$ magnification, $2 \mathrm{C}$ at $200 \mathrm{X}$ magnification, and $2 \mathrm{D}$ at $400 \mathrm{X}$ magnification.

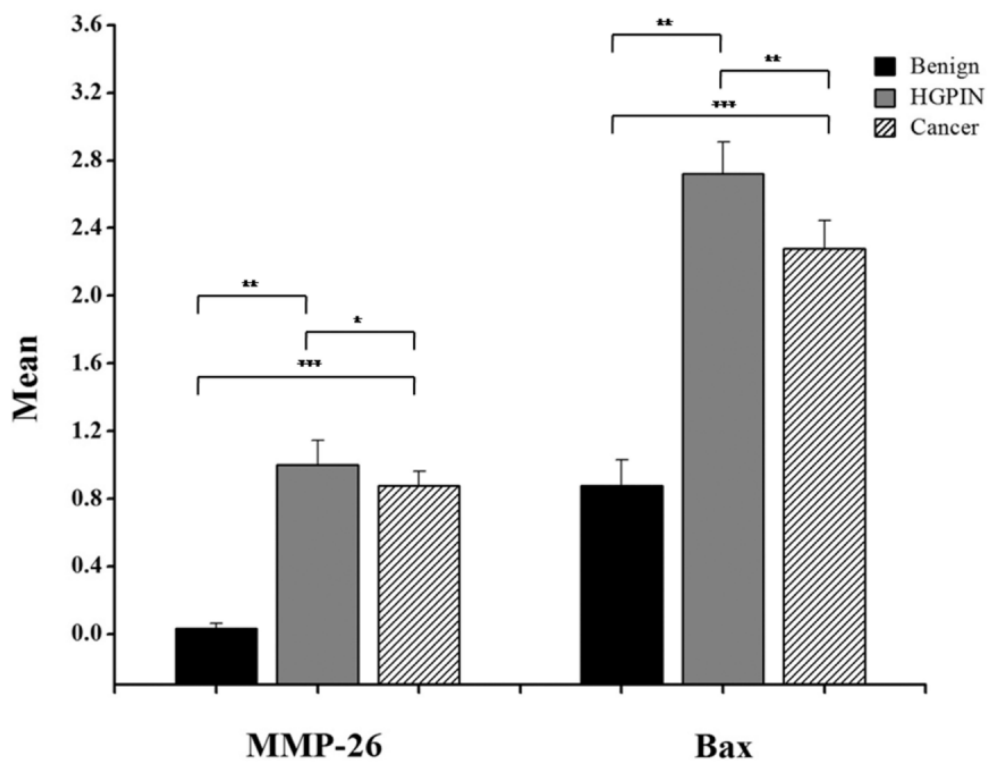

Figure 3: Bar graph of MMP-26 and Bax expression using immunohistochemical staining of 16 benign glands, 9 HGPIN tissues, and 16 invasive prostate cancer tissues. Statistical significance is shown as error bars reflect the standard error of the data. $* * *: p<0.0001$, **: $p<0.01$ and *: $p=0.5$. 
To further confirm the relationship between MMP-26 and apoptosis, an in situ apoptosis assay was used to detect apoptotic cells by labeling and detecting DNA strand breaks via the indirect TUNEL method. Consistently, the high expression of MMP-26 in human prostatic intraepithelial neoplasia, the most likely prostate cancer precursor, was directly related

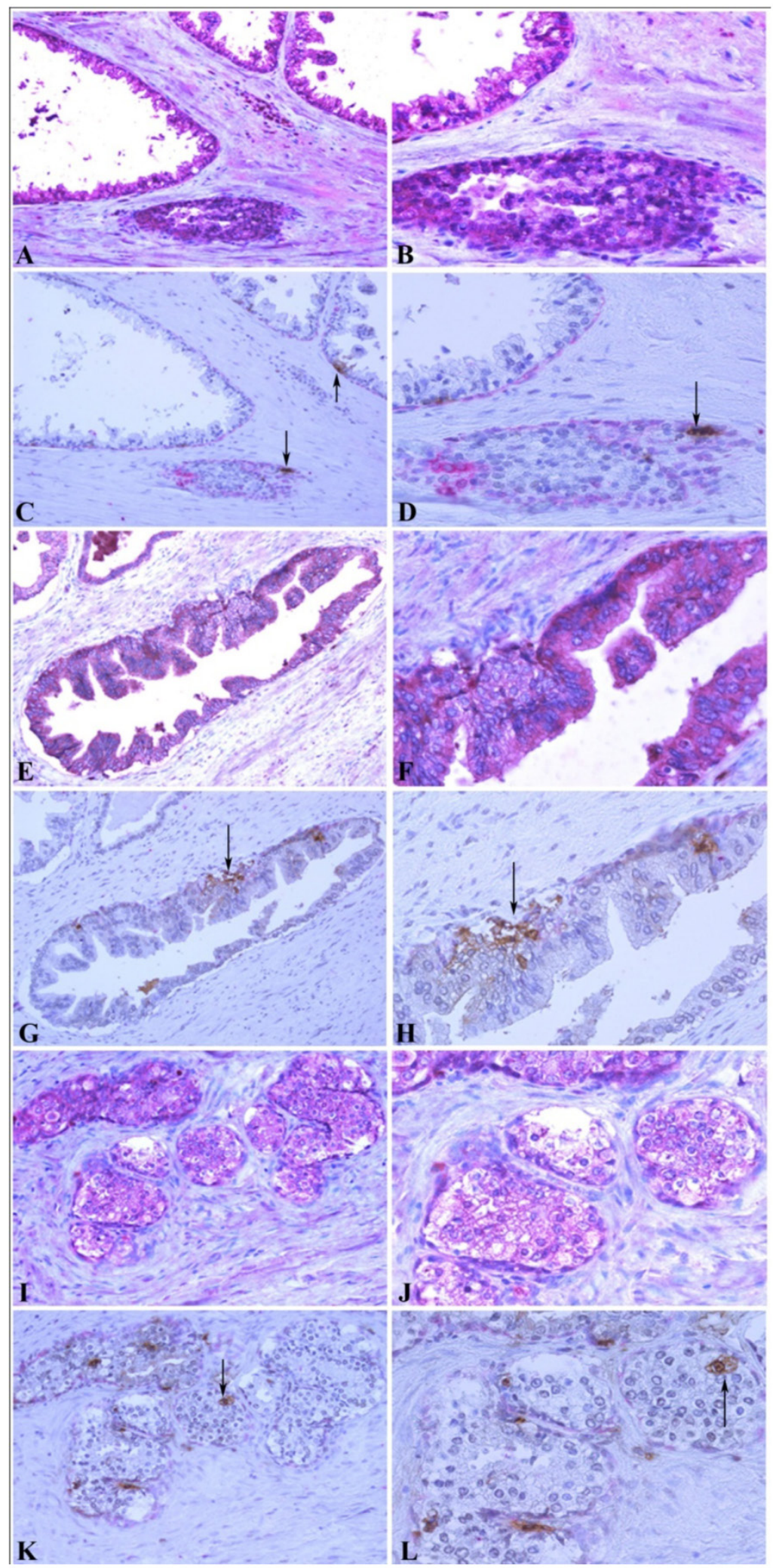

to apoptotic cell availability. Cancer cells expressing MMP-26 were found to be undergoing apoptosis. In adjacent sections, staining was done for MMP-26 expression and apoptosis. The expression of MMP-26 was diffuse in most neoplastic cells (Fig. 4). Double immunostaining for the basal cell layer marker, cytokeratin 34ßE12, and apoptosis showed that apoptosis was mainly seen in basal cells in benign glands with an intact basal layer (Fig. $4 \mathrm{~A}-4 \mathrm{D})$, and they were observed in cancer with absent basal cell layers (Fig. 4I-4L). In HGPIN where MMP-26 expression is the highest, the tissues showed higher immunoreactivity to apoptosis (Fig. 4E-4H). Tumor cells expressing MMP-26 had positively stained nuclei suggesting that they were subject to cell death (Fig. 4).

Bax up-regulation is sufficient to induce apoptosis [39]. The positive correlation between MMP-26 and Bax suggests that MMP-26 might play a protective role in tumors by promoting apoptosis via Bax. Many human prostate cancer tissues and cells have TP53 mutations that inactivate the tumor suppressor p53 [40]. ARCaP cells have a stop codon mutation from CGA to TGA in TP53 gene (Ala196end) that does not produce a functional p53 protein [40]. Therefore, it is unlikely that MMP-26 promotes apoptosis via p53 pathway. The detailed molecular mechanisms that MMP-26 may facilitate apoptosis remain to be further investigated.

Figure 4: Correlation between MMP-26 expression and apoptosis. Paraffin sections from human prostate were assessed for MMP-26 expression (red) as shown in panels A, B, E, F, I, and J. The adjacent slides were double-stained for cytokeratin $34 \beta E 12$ (red) and TUNEL apoptosis assay (brown) as shown in C, D, G, H, K, and L. Arrows show the apoptotic cells. Benign glands had moderate, diffuse MMP-26 (A-B) and rare apoptotic cells (C-D) with an intact basal cell layer. HGPIN had stronger MMP-26 staining (E-F) and a higher number of apoptotic cells (G-H). Cancerous tissue has lost the basal cells with lower MMP-26 expression (I-J) and frequent apoptotic cells (K-L). The same cancer cells with MMP-26 expression also appear to be undergoing apoptosis. Images on the left side were taken at 200X magnification and images on the right side were taken at $400 \mathrm{X}$ magnification.

\section{Conclusions}

Our results suggest a pro-apoptotic mode of action of MMP-26 in prostate cancer cells and tissues. This finding suggests a protective and anti-tumorigenic role for this protease in prostate cancer and can explain its high level in HGPIN and low level in the latest stages of cancer progression. Through induction of apoptosis, MMP-26 stimulates 
the selection of cells that are resistant to apoptosis. Whether the possible pro-apoptotic ability of MMP-26 that we have demonstrated in prostate cancer is tissue-dependent warrants further investigation. This will also include determining the mechanism of action of MMP-26 in the proteolytic cascade, the type of molecules involved in the process, and whether apoptosis occurs due to an upstream event activated by MMP-26 in the nucleus. These data have shifted the conventional view of MMP-26 as a major promoter of prostate cancer invasion and elucidated some of the beneficial roles of this protease in cancer progression. Deciphering more functions of this unique MMP may facilitate the design of more effective drugs to treat cancer patients.

\section{Acknowledgment}

The authors thank Dr. Kathleen C. Torkko in the Departments of Pathology and Epidemiology at University of Colorado, Denver, CO for statistical support. We are grateful to Dr. Leland W.K. Chung at Samuel Oschin Comprehensive Cancer Institute, Cedars-Sinai Medical Center, Los Angeles, for his continuous support to our prostate cancer research projects. This work was in part supported by grants from the Florida State University and an Endowed Chair Professorship in Cancer Research from anonymous donors to Dr. Sang.

\section{Competing Interests}

The authors have declared that no competing interest exists.

\section{References}

1. Amălinei C, Căruntu ID, Giuçă SE, Bălan RA. Matrix metalloproteinases involvement in pathologic conditions. Rom. J. Morphol. Embryol. 2010; 51 (2): 215-228.

2. Sang Q-X, Jin Y, Newcomer RG, Monroe SC, Fang X, Hurst DR, et al. Matrix metalloproteinase inhibitors as prospective agents for the prevention and treatment of cardiovascular and neoplastic diseases. Curr. Top. Med. Chem. 2006; 6 (4): 289-316.

3. Mu D, Cambier S, Fjellbirkeland L, Baron JL, Munger JS, Kawakatsu H, et al. The integrin $\operatorname{av} \beta 8$ mediates epithelial homeostasis through MT1-MMP-dependent activation of TGF- $\beta 1$. J. Cell Biol. 2002; 157 (3): 493-507.

4. $\mathrm{Yu} \mathrm{Q}$, Stamenkovic I. Cell surface-localized matrix mealloproteinase-9 proteolytically activates TGF-beta and promotes tumor invasion and angiogenesis. Genes Dev. 2000; 14: 163-176.

5. Friedl P, Wolf K. Proteolytic interstitial cell migration: A five-step process. Cancer Metastasis Rev. 2009; 28 (1-2): 129-135.

6. Friedl $\mathrm{P}$, Wolf K. Tube travel: The role of proteases in individual and collective cancer cell invasion. Cancer Res. 2008; 68 (18): 7247-7249.

7. Boire A, Covic L, Agarwal A, Jacques S, Sherifi S, Kuliopulos A. PAR1 is a matrix metalloprotease-1 receptor that promotes invasion and tumorigenesis of breast cancer cells. Cell 2005; 120 (3): 303-313.

8. Trivedi V, Boire A, Tchernychev B, Kaneider NC, Leger AJ, O'Callaghan K, et al. Platelet Matrix Metalloprotease-1 Mediates Thrombogenesis by Activating PAR1 at a Cryptic Ligand Site. Cell 2009; 137 (2): 332-343.

9. Roycik MD, Myers JS, Newcomer RG, Sang Q-X. Matrix metalloproteinase inhibition in atherosclerosis and stroke. Curr. Mol. Med. 2013; 13 (8): 1299-313.

10. Hu J, Van den Steen PE, Sang Q-X a, Opdenakker G. Matrix metalloproteinase inhibitors as therapy for inflammatory and vascular diseases. Nat. Rev. Drug Discov. 2007; 6 (6): 480-498

11. Martin MD, Matrisian LM. The other side of MMPs: protective roles in tumor progression. Cancer metastasis Rev. 2007; 26 (3-4): 717-724.
12. McCawley LJ, Crawford HC, King Jr LE, Mudgett J, Matrisian LM. A protective role for matrix metalloproteinase-3 in squamous cell carcinoma. Cancer Res. 2004; 64 (19): 6965-6972.

13. Balbín M, Fueyo A, Tester AM, Pendás AM, Pitiot AS, Astudillo A, et al. Loss of collagenase-2 confers increased skin tumor susceptibility to male mice. Nat. Genet. 2003; 35 (3): 252-257.

14. Kerkelä E, Ala-aho R, Klemi P, Grénman S, Shapiro SD, Kähäri V, et al. Metalloelastase (MMP-12) expression by tumour cells in squamous cell carcinoma of the vulva correlates with invasiveness, while that by macrophages predicts better outcome. J. Pathol. 2002; 198 (2): 258-269.

15. Coussens LM, Tinkle CL, Hanahan D, Werb Z. MMP-9 supplied by bone marrow-derived cells contributes to skin carcinogenesis. Cell 2000; 103 (3): 481-490.

16. Agarwal D, Goodison S, Nicholson B, Tarin D, Urquidi V. Expression of matrix metalloproteinase 8 (MMP-8) and tyrosinase-related protein-1 (TYRP-1) correlates with the absence of metastasis in an isogenic human breast cancer model. Differentiation 2003; 71 (2): 114-125.

17. Si-Tayeb K, Monvoisin A, Mazzocco C, Lepreux S, Decossas M, Cubel G, et al. Matrix metalloproteinase 3 is present in the cell nucleus and is involved in apoptosis. Am. J. Pathol. 2006; 169 (4): 1390-1401.

18. Hockenbery DM. MMPs in unusual places. Am. J. Pathol. 2006; 169 (4): 1101-1103.

19. Lovett DH, Mahimkar R, Raffai RL, Cape L, Zhu BQ, Jin ZQ, et al. N-Terminal Truncated Intracellular Matrix Metalloproteinase-2 Induces Cardiomyocyte Hypertrophy, Inflammation and Systolic Heart Failure. PLoS One 2013; 8 (7): 1-14.

20. Park HI, Ni J, Gerkema FE, Liu D, Belozerov VE, Sang QX. Identification and characterization of human endometase (Matrix metalloproteinase-26) from endometrial tumor. J. Biol. Chem. 2000; 275 (27): 20540-20544.

21. Benoit de Coignac A, Elson G, Delneste Y, Magistrelli G, Jeannin P, Aubry J, et al. Cloning of MMP-26. Eur. J. Biochem. 2000; 267 (11): 3323-3329.

22. Uria JA, Lopez-Otin C. Matrilysin-2, a new matrix metalloproteinase expressed in human tumors and showing the minimal domain organization required for secretion, latency, and activity. Cancer Res. 2000; 60 (17): $4745-4751$.

23. Marchenko G, Ratnikov B, Rozanov D, Godzik A, Deryugina E, Strongin A. Characterization of matrix metalloproteinase-26, a novel metalloproteinase widely expressed in cancer cells of epithelial origin. Biochem.J 2001; 356: 705-718.

24. Park HI, Turk BE, Gerkema FE, Cantley LC, Sang QX. Peptide substrate specificities and protein cleavage sites of human endometase/matrilysin-2/matrix metalloproteinase-26. J. Biol. Chem. 2002; 277 (38): 35168-35175.

25. Marchenko ND, Marchenko GN, Weinreb RN, Lindsey JD, Kyshtoobayeva A, Crawford $\mathrm{HC}$, et al. $\beta$-Catenin regulates the gene of MMP-26, a novel matrix metalloproteinase expressed both in carcinomas and normal epithelial cells. Int. J. Biochem. Cell Biol. 2004; 36 (5): 942-956.

26. Tunuguntla R, Ripley D, Sang Q-X, Chegini N. Expression of matrix metalloproteinase-26 and tissue inhibitors of metalloproteinases TIMP-3 and-4 in benign endometrium and endometrial cancer. Gynecol. Oncol. 2003; 89 (3): 453-459.

27. Zhao Y, Xiao A, Park HI, Newcomer RG, Yan M, Man Y, et al. Endometase / Matrilysin-2 in Human Breast Ductal Carcinoma in Situ and Its Inhibition by Tissue Inhibitors of Metalloproteinases-2 and -4: A Putative Role in the Initiation of Breast Cancer Invasion. Cancer Res.. 2004; (850): 590-598.

28. Savinov AY, Remacle AG, Golubkov VS, Krajewska M, Kennedy S, Duffy MJ, et al. Matrix metalloproteinase 26 proteolysis of the NH2-terminal domain of the estrogen receptor beta correlates with the survival of breast cancer patients. Cancer Res. 2006; 66 (5): 2716-2724.

29. Lee S, Desai KK, Iczkowski KA, Newcomer RG, Wu KJ, Zhao Y-G, et al. Coordinated peak expression of MMP-26 and TIMP-4 in preinvasive human prostate tumor. Cell Res. 2006; 16 (9): 750-758.

30. Zhao YG, Xiao AZ, Newcomer RG, Park HI, Kang T, Chung LW, et al. Activation of pro-gelatinase B by endometase/matrilysin-2 promotes invasion of human prostate cancer cells. J. Biol. Chem. 2003; 278 (17): 15056-15064.

31. Khamis ZI, Zorio D a. R, Chung LWK, Sang Q-X. The Anti-inflammatory Role of Endometase/Matrilysin-2 in Human Prostate Cancer Cells. J. Cancer 2013; 4 (4): 296-303.

32. Harris HA, Albert LM, Leathurby Y, Malamas MS, Mewshaw RE, Miller CP, et al. Evaluation of an estrogen receptor- $\beta$ agonist in animal models of human disease. Endocrinology 2003; 144 (10): 4241-4249.

33. Mannello F, Luchetti F, Falcieri E, Papa S. Multiple roles of matrix metalloproteinases during apoptosis. Apoptosis 2005; 10 (1): 19-24.

34. Khamis ZI, Iczkowski KA, Sahab ZJ, Sang QX. Protein profiling of isolated leukocytes, myofibroblasts, epithelial, Basal, and endothelial cells from normal, hyperplastic, cancerous, and inflammatory human prostate tissues. J. Cancer 2010; 1: 70-79.

35. Lockshin RA, Zakeri Z. Caspase-independent cell death? Oncogene 2004; 23 (16): 2766-2773.

36. Powell WC, Fingleton B, Wilson CL, Boothby M, Matrisian LM. The metalloproteinase matrilysin proteolytically generates active soluble Fas ligand and potentiates epithelial cell apoptosis. Curr. Biol. 1999; 9 (24): 1441-1447. 
37. Mitsiades N, Yu WH, Poulaki V, Tsokos M, Stamenkovic I. Matrix metalloproteinase-7-mediated cleavage of Fas ligand protects tumor cells from chemotherapeutic drug cytotoxicity. Cancer Res. 2001; 61 (2): 577-581.

38. Witty JP, Lempka T, Coffey Jr RJ, Matrisian LM. Decreased tumor formation in 7,12-dimethylbenzanthracene-treated stromelysin- 1 transgenic mice is associated with alterations in mammary epithelial cell apoptosis. Cancer Res. 1995; 55 (7): 1401-1406.

39. Del Re DP, Miyamoto S, Brown JH. RhoA/Rho kinase up-regulate Bax to activate a mitochondrial death pathway and induce cardiomyocyte apoptosis. J. Biol. Chem. 2007; 282 (11): 8069-8078.

40. van Bokhoven A, Varella-Garcia M, Korch C, Johannes WU, Smith EE, Miller HL, Nordeen SK, Miller GJ, Lucia MS. Molecular characterization of human prostate carcinoma cell lines. Prostate. 2003; 57(3): 205-225. 